\title{
A crise dentro da crise: aceleração e pandemia
}

\author{
Arthur Bueno * \\ * GOETHE-UNIVERSITÄT FRANKFURT
}

\section{Apresentação}

Esta Intervenção se dedica a analisar a pandemia da Covid-19 como uma crise da aceleração. Se a disseminação do vírus demandou de início - como argumentou Hartmut Rosa - uma “desaceleração forçada" de amplos setores da vida social, as várias reações que se seguiram a esse evento também podem ser entendidas nos termos de diferentes experiências temporais: "desaceleração imersiva”, "desaceleração angustiada", "reaceleração exasperada" e “desaceleração planejada".

\section{Retorno à normalidade?}

Não foram poucas as vezes em que ouvimos falar, nos últimos meses, de um ansiado - e a cada vez novamente adiado - "retorno à normalidade". Se em março de 2020 o mundo pareceu ter freado bruscamente, nada mais natural do que esperar que, em algum momento, ele voltasse a mover-se como antes. Mas que normalidade é essa? Mesmo antes da pandemia, multiplicavam-se os sinais de crise: do colapso financeiro de 2008 aos protestos políticos da década seguinte, da escalada preocupante das mudanças climáticas à emergência de uma nova onda de extrema direita, múltiplos eventos já indicavam que nossa sociedade não podia mais simplesmente seguir nos seus trilhos usuais sem que, para falar como Gramsci, emergissem um conjunto de "sintomas mórbidos". ${ }^{1}$ A crise sanitária da covid-19 irrompeu em meio a um mundo já em crise; ela representou "um tremendo abalo e desestabilização estrutural"² de um sistema global que não parecia, afinal, caminhar tão bem. Introduziu-se assim um corte

\footnotetext{
${ }^{1}$ Antonio Gramsci, Cadernos do cárcere, vol. 3 (Rio de Janeiro: Civilização Brasileira, 2007), 184.

${ }^{2}$ Hartmut Rosa, "La sociedad ante la desaceleración forzada: Una interpretación sociológica de la crisis del coronavirus", Diferencia(s): Revista de teoría social contemporánea 11 (2020): 21.
} 
temporal abrupto na experiência social: a emergência inesperada da pandemia conduziu, nos termos de Hartmut Rosa, à "desaceleração forçada" de uma sociedade pautada pelo princípio da "estabilização dinâmica", cujas principais instituições só podem manter-se graças a (e ao custo de) um constante esforço de crescimento, em ritmo cada vez mais veloz. ${ }^{3}$ Os abalos do presente não concernem, porém, simplesmente uma sociedade estruturada segundo processos de estabilização dinâmica. Se a constituição desse tipo de ordem social coincide com o próprio advento da modernidade, ${ }^{4}$ é preciso ter em vista que nos situamos agora em uma etapa específica desse desenvolvimento. As instituições que se viram sacudidas pela irrupção da pandemia são aquelas de um capitalismo global consolidado nas últimas décadas do século 20. Nesse período, a experiência da aceleração social assumiu uma feição particular, em linha com uma nova forma de subjetividade que veio a se estabelecer como dominante. Seja seu Best Self: Be You, Only Better - esse é o imperativo característico da "nova individualidade" " que emergiu graças à confluência de um regime de acumulação pós-fordista e financeirizado com a disseminação de ideais neorromânticos de autenticidade pessoal. Dos sujeitos não se espera mais que obedeçam de maneira dócil a normas disciplinares, mas antes que se portem como "empresários de si" capazes de obter sucesso mercantil por meio da sustentação de uma vida singular - tanto autodescoberta quanto inventada, tanto autêntica quanto otimizada, tanto emocionalmente comunicativa quanto adaptada de maneira flexível às condições cambiantes do mercado. ${ }^{7}$

Não é por acaso que justamente nesse período tenha emergido um interesse renovado pela crítica da aceleração. As transformações da segunda metade do século 20 resultaram num incremento ainda maior da velocidade do ritmo da vida que Marx, Baudelaire, Simmel e tantos outros observaram entre meados do século 19 e o início do século seguinte. Se então "tudo o que era sólido" se liquefazia até "desmanchar-se no ar", o capitalismo das últimas

\footnotetext{
${ }^{3}$ Ibid., 21-2.

${ }^{4}$ Hartmut Rosa, Beschleunigung: Die Veränderung der Zeitstrukturen in der Moderne (Frankfurt am Main: Suhrkamp, 2005); Hartmut Rosa, "Dynamic Stabilization, the Triple A Approach to the Good Life, and the Resonance Conception", Questions de communication 31 (2017), 437-56.

5 Título de um best-seller de auto-ajuda: Mike Bayer, Best Self: Be You, Only Better (New York: Dey Street Books, 2019).

${ }^{6}$ Axel Honneth, "Organized Self-realization: Some Paradoxes of Contemporary Individualization”, European Journal of Social Theory 7, no. 4 (2004): 470.

${ }^{7}$ Luc Boltanski, Ève Chiapello, Le nouvel esprit du capitalisme (Paris: Gallimard, 1998); Richard Sennett, The Corrosion of Character: The Personal Consequences of Work in the New Capitalism (London/New York: W. W. Norton \& Company, 1998); Ulrich Bröckling, Das unternehmerische Selbst: Soziologie einer Subjektivierungsform (Frankfurt am Main: Suhrkamp, 2007); Pierre Dardot, Christian Laval, La nouvelle raison du monde. Essai sur la société néolibérale (Paris: La Découverte, 2009); Andreas Reckwitz Die Gesellschaft der Singularitäten: Zum Strukturwandel der Moderne (Berlin: Suhrkamp, 2017).
} 
décadas pareceu nos conduzir a uma modernidade ainda mais "líquida". ${ }^{8}$ Intensificou-se, assim, a sensação de vivermos num estado de "estagnação frenética" pudéssemos parar de tentar subir uma escala rolante que segue constantemente para baixo. Somos impelidos a seguir avançando a passos sempre mais rápidos, de preferência mais rápidos que os dos demais, em condições que nos levam, contudo, a sentir que não estamos indo a lugar algum. É a essa normalidade que se pretende retornar?

\section{Aceleração, depressão e a crise da subjetividade neoliberal}

Não surpreende que as taxas de depressão tenham crescido tanto nesse período. A experiência depressiva marca, com efeito, o ponto em que a exigência de ser um empresário de si veloz e eficiente se torna subjetivamente problemática: quando a promessa de autenticidade se transforma em vazio e falta de sentido, quando a busca por autodeterminação resulta em sentimentos de impotência. Pressionado pelo imperativo de descobrir e inventar seu "melhor eu" - uma versão otimizada, flexível e acelerada de si mesmo -, o empreendedor se converte então no indivíduo depressivo, exaurido e "sem gás". O sujeito disciplinar ainda se movia num mundo organizado pela oposição entre o permitido e o proibido, a autoridade da lei e a força dos impulsos reprimidos; seu sofrimento psíquico, como indicam os escritos de Freud, manifestava-se sobretudo em sentimentos de culpa. Ao indivíduo depressivo, por sua vez, tudo é aparentemente permitido, e no entanto ele se sente incapaz de dar conta de toda a gama de possibilidades disponíveis. Seu mal-estar deriva antes de sentimentos de insuficiência (cansaço, vazio, incapacidade de agir etc.) do que de culpa; ele remete menos aos polos do permitido e do proibido do que à oposição entre o possível e o impossível. ${ }^{10} \mathrm{~A}$ experiência é, assim, acelerada: não havendo a princípio limites para o sucesso e a otimização pessoais, o indivíduo tem de manter-se atualizado, "reciclado", a cada dia mais rápido, eficiente e “realizado". O recuo do conflito entre o permitido e o proibido, deslocado pela oposição entre o possível e o impossível, resultou numa submissão mais imediata do sujeito às flutuações dos mercados, eles próprios movendo-se com rapidez cada vez maior. Daí que justamente na

\footnotetext{
${ }^{8}$ Karl Marx e Friedrich Engels, O Manifesto Comunista (Porto Alegre: L\&PM Pocket, 2001), 29; Zygmunt Bauman, Liquid Modernity (Cambridge: Polity, 1999).

9 A expressão deriva do título da edição alemã (Rasender Stillstand) do livro de Paul Virilio, L'Inertie polaire (Paris: C. Bourgois, 1990).

${ }^{10}$ Alain Ehrenberg, La fatigue d'être soi: Dépression et société (Paris: Odile Jacob, 1998); ver também Byung-Chul Han, Müdigkeitsgesellschaft (Berlin: Matthes \& Seitz, 2010).
} 
segunda metade do século 20, como indica Hartmut Rosa, a velocidade das mudanças nos modos de vida tenha alcançado um novo patamar:

$\mathrm{Na}$ modernidade tardia, (...) a velocidade da mudança social ultrapassa a barreira do som e se torna, por assim dizer, intrageracional: não sabemos mais como as relações sociais poderão estar ao final de nossa vida. As profissões não duram mais a vida inteira, o parceiro para a vida se torna, segundo essa tendência, parceiro de parte da vida, as preferências políticas mudam a cada eleição, também o plano de saúde e o tipo de investimento monetário não permanecem estáveis ao longo da vida profissional. A consequência: agora (...) a duração, a sequência e o momento de ações e eventos (por exemplo, períodos da formação escolar, casamento, filhos, fases de desemprego, mas também planos do dia a dia) são decididos de maneira móvel, em processo, a cada situação. Tudo isso não pode mais ser planejado antecipadamente. A vida se torna, nesse sentido, "destemporalizada": hoje é assim; amanhã tudo, inclusive os próprios desejos, pode ser diferente. ${ }^{11}$

A depressão indica o limite psicossocial dessa dinâmica temporal: o indivíduo se exaure de tanto buscar obter sucesso mercantil e simultaneamente "ser si mesmo"; seu corpo desiste, renuncia ao imperativo de otimizar-se, força uma desaceleração. Com isso ainda não se chegou, todavia, ao limite institucional desse processo. É constitutiva dessa ordem, afinal, a oscilação contínua entre duas experiências temporais: a de um empresário de si confiante em sua capacidade de reinventar-se, de ajustar-se flexivelmente às flutuações do mercado; e a de um indivíduo depressivo que, fracassando reiteradamente em alcançar tais objetivos, interrompe essa dinâmica (adoecendo) ou a põe definitivamente a termo (cometendo suicídio). A desaceleração depressiva está conectada de maneira intrínseca à aceleração empresarial. Ambas formam em conjunto a "normalidade" da ordem instituída entre os anos 1960 e as primeiras décadas do século 21 - uma normalidade contraditória, problemática, prenhe de sofrimentos e crises, e no entanto capaz de manter certo grau de estabilidade.

Nos últimos anos, contudo, esse arranjo social passou a manifestar sinais cada vez mais pronunciados de exaustão, até o ponto em que puderam ser reconhecidos, finalmente, os índices de uma crise generalizada. Esta última diz respeito não apenas aos modos de organização econômica e política que vieram a prevalecer nas últimas décadas, mas também a

\footnotetext{
${ }^{11}$ Hartmut Rosa, “Contra a invisibilização de um 'poder fatídico': apelo à renovação da crítica do capitalismo”, Perspectivas: Revista de Ciências Sociais 49 (2017), 27-28. Grifos no original.
} 
formas correspondentes de experiência psicossocial. Ela põe em xeque não só as instituições vigentes, mas também nossos modos de agir, pensar e sentir. É no quadro dessa crise - a crise da subjetividade neoliberal - que se podem, logo, compreender fenômenos como a onda de protestos dos anos 2010 e a ascensão recente do autoritarismo de extrema-direita. ${ }^{12} \mathrm{E}$ é esse mundo já em crise que foi abalado pela Covid-19. Não espanta que a pandemia tenha suscitado reações psicossociais tão diversas e, muitas vezes, tão disparatadas, com a emergência de negacionismos e teorias conspiratórias de vários tipos. A crise sanitária sacudiu bruscamente, afinal, uma sociedade já em estado de exaustão.

\section{Promessas e fracassos da subjetividade neoliberal}

Se quisermos entender as diferentes reações incitadas pela crise sanitária atual, temos, portanto, de nos voltar às tensões não resolvidas da individualidade neoliberal, oscilando entre os polos do empresário de si e da pessoa depressiva. Tais tensões remontam a duas promessas centrais dessa forma de subjetividade.

A primeira é a de que seria possível alcançar a autodeterminação por meio da iniciativa empresarial: oferecendo um produto inovador em um dos vários mercados dos quais a vida social é agora composta, estaríamos em condições de imprimir neles a nossa marca pessoal e transformá-los à nossa imagem e semelhança - "quebrando paradigmas", segundo uma expressão corriqueira no universo corporativo. O empresário de si difere a esse respeito do sujeito disciplinar. Em lugar de se provar como um ser autônomo afirmando capacidades que possui como membro geral da espécie humana, o indivíduo neoliberal busca fazê-lo empregando forças criativas que possam torná-lo singular em relação aos outros. No entanto, o fracasso reiterado na realização dessa promessa - em razão do funcionamento altamente desigual dos mercados e da situação com frequência precarizada de tais empresários - leva a uma forte sensação de que se está submetido a um conjunto de leis pré-determinadas, muitas vezes difíceis de entender e de modificar. Ao esforço empreendedor de "quebrar paradigmas" contrapõe-se, então, a percepção depressiva de que "Não há alternativa". Daí que a depressão possa ser concebida, nos termos de Alain Ehrenberg, como uma "doença da autonomia": ${ }^{13}$

\footnotetext{
${ }^{12}$ Arthur Bueno, “¿Qué viene después de la depresión? Ocho tesis sobre la crisis de la subjetividad neoliberal y sus implicancias políticas”, Cuadernos de Teoría Social 6, no. 11 (2020): 95-120.

${ }^{13}$ Alain Ehrenberg, "La dépression, maladie de l'autonomie? Interview d'Alain Ehrenberg”, Nervure 16, no. 3 (2003): 35-40.
} 
buscando autodeterminar-se por meio de uma iniciativa empresarial capaz de transformar o mundo à sua imagem e semelhança, o indivíduo depressivo acaba por ver-se submetido a leis aparentemente inescapáveis e fatais.

Mas há uma segunda promessa própria à subjetividade neoliberal. Também inerente a ela é a ideia de que existe um vínculo inextricável entre sucesso mercantil e autenticidade subjetiva: é por meio da atividade mercantil que o indivíduo explora e transforma seus impulsos mais íntimos, descobre e inventa seu (melhor) eu. A efetivação de uma conexão significativa consigo mesmo e com o mundo seria posta à prova e comprovada diretamente por meio da concorrência mercantil. O indivíduo, na medida em que consegue vender seus produtos e a si mesmo em mercados de vários tipos (não apenas econômicos no sentido estrito, mas também em mercados por atenção, influência ou prestígio), acabaria demonstrando sua capacidade de estabelecer uma continuidade afetiva entre si mesmo e os outros. A autenticidade é uma conquista mercantil.

Também neste aspecto o empresário de si difere de maneira importante em relação ao sujeito disciplinar. Se este último buscava autorrealização referindo-se a uma personalidade nuclear concebida como íntima, até mesmo insondável, e como tal em grande medida mantida à parte do escrutínio público, o indivíduo neoliberal veio a fazê-lo pela mobilização orientada para o sucesso de capacidades afetivas vistas como abertas à transformação e permeáveis à avaliação externa: elas são "inventadas" tanto quanto "descobertas". No entanto, a promessa de conexão afetiva com os outros tende a ser minada pela estruturação da vida social como uma competição mercantil entre indivíduos atomizados - uma tendência sintetizada, mais uma vez, por um dos motes de Thatcher: "A sociedade não existe". A exigência de que cada pessoa seja um indivíduo autossuficiente resultou em sentimentos crescentes de isolamento e fragmentação social. Por isso a depressão também pode ser caracterizada como uma "doença da autenticidade": procurando estabelecer uma conexão afetiva consigo mesmo e com o mundo por meio da descoberta e invenção de uma identidade própria, o indivíduo depressivo acaba por ver-se isolado em meio a um mundo dominado pela concorrência.

A experiência depressiva aponta, assim, em negativo, para as promessas fracassadas da subjetividade empresarial-neoliberal. Ambas as figuras constituem, como vimos, a normalidade característica da ordem estabelecida nas últimas décadas. E no entanto, o colapso financeiro de 2008, a onda de protestos dos anos 2010 e a ascensão da nova extrema direita levaram essa dinâmica a outro nível. As tensões sociais implícitas assumiram, então, a forma 
explícita de uma crise. Para além da oscilação entre as posições do empresário de si e do indivíduo depressivo, viu-se emergir, em resposta aos conflitos da normalidade neoliberal, o que podemos chamar de uma constelação pós-depressiva: isto é, um conjunto de tendências políticas variadas que reagem às tensões da subjetividade neoliberal e apontam, ao menos potencialmente, para outras formas de organização social e de experiência psíquica. ${ }^{14}$

Como argumentei com mais detalhe em outro texto, ${ }^{15}$ uma dessas tendências veio à luz nos protestos políticos dos anos 2010 - da Primavera Árabe ao Occupy Wall Street, das Jornadas de Junho de 2013 no Brasil aos “coletes amarelos" na França. Em resposta ao fatalismo e à fragmentação social característicos da subjetividade neoliberal, experimentou-se então, mesmo que apenas por alguns momentos, o sentimento de que seria possível suspender a ordem normativa vigente e participar ativamente da constituição de um novo arranjo social, bem como tomar parte numa comunhão afetiva formada na e pela diversidade. Contudo, o caráter vago e efêmero desses movimentos, aliado à correspondente indeterminação de suas consequências políticas, acabou de modo geral por contribuir para uma sensação ainda mais intensa de deslegitimação e crise da ordem neoliberal. É nesse contexto que emergiu com força crescente uma nova extrema-direita - a qual pode, assim, ser considerada como outra expressão da situação pós-depressiva. Reagindo à deslegitimação das instituições neoliberais e à sensação correspondente de anomia, esse novo autoritarismo não propõe uma suspensão das normatividades vigentes (como nos protestos dos anos 2010), mas sim uma ordem repressiva capaz de afirmar-se com a coerção ou violência necessárias para manter sua eficácia. Em resposta à sensação crescente de fragmentação social, por sua vez, tais movimentos não defendem a constituição de um "comum" indeterminado (como nas experiências da década de 2010), mas sim concepções mais uniformes e excludentes de comunhão nacional. Esse novo autoritarismo é, no entanto, paradoxal: reagindo à crise da subjetividade neoliberal e extraindo daí sua força opositora, "antissistêmica", ele se esforça por todos os meios para continuar, e até mesmo radicalizar, essa mesma forma de subjetividade. Precisamente nessa estrutura paradoxal - uma tentativa de ir além da depressão que reinstala as condições da depressão - reside uma das fontes de seu enorme potencial destrutivo.

A efervescência coletiva dos protestos dos anos 2010 e o novo autoritarismo neoliberal constituem, assim, dois (dentre outros) fenômenos políticos que emergiram

\footnotetext{
${ }^{14}$ Bueno, “¿Qué viene después de la depresión?".

${ }^{15}$ Ibid.
} 
recentemente em reação às promessas fracassadas da subjetividade neoliberal. Todavia, na medida em que tais tendências se mostraram incapazes de mudar esse estado de coisas (efervescência coletiva) ou representam sua continuação por outros meios e de maneira ainda mais obstinada (autoritarismo), as tensões da ordem neoliberal mantêm-se atuantes, assim como suas implicações psicossociais.

\section{Crise sanitária e desaceleração forçada}

Foi nesse contexto que, no início de 2020, a pandemia emergiu. A rápida disseminação da Covid-19 suscitou, então, prognósticos sombrios a tal ponto que o impensável se tornou realidade: a paralização ou restrição significativa de amplos setores e cadeias da atividade econômica em escala global. De um momento a outro, a ideia de que o ritmo da vida capitalista pudesse desacelerar-se não pareceu mais tão absurda. Pelo contrário, ela se tornava palpável na experiência de muitos de nós. As consequências não foram certamente as mesmas para todos: em diversas áreas, a começar pela saúde pública, as demandas por velocidade se multiplicaram. Entretanto, o saldo global foi, nesse primeiro momento, o de uma desaceleração brusca da vida capitalista. Mais do que repentina, essa desaceleração foi também, como apontou Hartmut Rosa, forçada. ${ }^{16}$ Ela não se deu graças a uma decisão coletiva com vistas a reduzir os efeitos destrutivos da aceleração, mas sobretudo em resposta às ameaças estabelecidas pelo vírus à nossa sobrevivência bem como à reprodução da própria economia capitalista.

Irrompia, então, uma crise de aspecto muito similar àquela descrita por Lukács em História e consciência de classe: a saber, como um momento no qual a coerência racional da ordem capitalista é perturbada pelo surgimento repentino de uma contingência concreta, material, que não pode ser administrada racionalmente pelo sistema e, portanto, revela a contingência do próprio sistema. As "leis naturais" da sociedade capitalista se mostram, então, como as "leis do acaso". ${ }^{17}$ Ao ameaçar a nossa forma de vida, a crise aponta assim para a própria historicidade do nosso mundo. Os perigos da Covid-19 só são globais porque o capitalismo tornou-se, ele mesmo, cada vez mais global. Foi graças a suas aceleradas cadeias de valor que o vírus pôde circular por toda parte com tamanha rapidez. A pandemia revela,

\footnotetext{
${ }^{16}$ Rosa, "La sociedad ante la desaceleración forzada", 21-2.

${ }^{17}$ Georg Lukàcs, História e consciência de classe: estudos sobre a dialética marxista (São Paulo: Martins Fontes, 2003), 224.
} 
além disso, o quanto somos determinados por um futuro abstrato: o de uma acumulação capitalista girando em ritmo cada vez mais veloz. O aspecto desastroso de uma mera desaceleração desse sistema, mesmo que momentânea, mostra em que medida nossa forma de vida depende, para manter-se, de uma tendência incessante à geração de valor. Um mundo regido pela estabilização dinâmica não pode diminuir sua velocidade sem correr o risco de desintegrar-se tal como é. E no entanto, a pandemia nos forçou exatamente a isso.

O caráter contingente da pandemia confere a ela, desse modo, tanto um lado ameaçador quanto um aspecto de abertura histórica. A disseminação da Covid-19 implicou um risco a nossos modos de vida bem como a possibilidade de sua transformação. Daí a intensidade das reações que ela suscitou, em variadas direções. O impacto desse acontecimento foi acentuado, além disso, pelo fato de que a crise sanitária emergiu num contexto já marcado por uma crise da subjetividade. A pandemia veio a abalar uma sociedade acelerada, cuja figura modelar, o empresário de si mesmo, começava a girar em falso e mostrar sinais de esgotamento. Nesse contexto, a irrupção da crise sanitária pôde ser sentida por muitos, ao menos provisionalmente, com certo alívio. Apesar de forçada, a desaceleração podia ser liberadora. Abria-se com ela, afinal, a possibilidade de repensar os rumos da aceleração característica da subjetividade neoliberal.

\section{Desaceleração imersiva, desaceleração angustiada}

As diferentes posturas suscitadas pela pandemia podem, então, ser lidas como reações à interrupção forçada da velocidade do nosso mundo, freado bruscamente sob impacto da contingência material do vírus. Nesse contexto, como destacou Slavoj Žižek, houve aqueles para quem nossa situação pôde parecer similar àquela descrita em A guerra dos mundos. Ao passo que na novela de H. G. Wells marcianos conquistam a Terra, mas são mortos por "humildes" patógenos aos quais não tinham imunidade, no contexto atual nós é que seríamos os marcianos: parasitas que exploram e destroem a vida no planeta e, no entanto, acabam ameaçados por "vírus estúpidos que só se multiplicam cegamente e sofrem mutações". ${ }^{18}$ Segundo uma tal narrativa redentora, o vírus teria vindo para punir a humanidade pela exploração impiedosa de outras formas de vida. A pandemia adquire, assim, um sentido grandioso: ela seria não somente liberadora com relação a uma sociedade já em crise, mas

\footnotetext{
${ }^{18}$ Slavoj Žižek, Pandemia: covid-19 e a reinvenção do comunismo (São Paulo: Boitempo, 2020), 30-1.
} 
também fatal - destrutiva e inescapável. Ela expiaria o nosso mundo da acumulação acelerada e viria para impor, contra os princípios estabelecidos, as leis de um novo mundo. Com suas ameaças, o vírus teria o condão de nos unir e, desse modo, também nos redimir.

A fantasia masoquista de que, como os marcianos de $A$ guerra dos mundos, estamos sendo punidos por algo que fizemos é reconfortante: ela instaura um sentido totalizante, situado para além de nós, e apazigua assim a insegurança associada à contingência da crise. $\mathrm{O}$ mesmo se dá na atitude - aparentemente oposta - de encontrar prazer sádico na noção de que a pandemia, com todo o sofrimento que ela provoca, ajudará automaticamente a "nossa causa". Em ambos os casos, assumimos uma posição de passividade na medida em que encaramos a contingência que interrompeu bruscamente o curso das nossas vidas como se ela fosse uma necessidade. Tal postura nos exime da responsabilidade de agir, ela nos coloca num estado de desaceleração imersiva: estamos sujeitos a um vírus mortal cujas dinâmicas parecem escapar ao nosso controle; ainda bem que ele veio para nos expiar e redimir, nos desacelerar e unir.

Essa posição é reconfortante, e no entanto nos impede de enfrentar a crise e reagir adequadamente a ela. Para tanto, seria preciso efetivamente reconhecer a contingência da ameaça existencial que a pandemia representa. Fazê-lo pode nos conduzir, entretanto, a outro risco: o de que venhamos a encarar as nossas próprias vidas como contingentes e desprovidas de sentido. Se no caso anterior a disseminação do vírus aparecia como uma totalidade determinada, já dotada de um sentido que nos ultrapassa, aqui ela assume o aspecto de um Outro todo-poderoso, indefinido, cuja ameaça invisível gera um sentimento agudo de vulnerabilidade. A pandemia não só ressalta o caráter contingente da vida de cada um de nós, o fato bruto de que podemos morrer ou adoecer a qualquer momento; ela também o intensifica, na medida em que torna as interações sociais contagiosas, arriscadas em suas consequências, potencialmente letais. Os gráficos com curvas ascendentes, as notícias sobre o adoecimento ou a morte de pessoas próximas ou conhecidas, a edição de novas medidas sanitárias, tudo isso vem a nos lembrar, dia a dia, da fragilidade da nossa existência. $\mathrm{O}$ vírus nos incita a tomar novas precauções, a nos recolhermos em nossas casas, a evitarmos o contato uns com os outros. Ele pode impelir, assim, a uma experiência de desaceleração não mais liberadora ou redentora, mas angustiada. Mesmo o tempo livre que se abriu para certas parcelas da população pôde, então, ser vivenciado não como uma liberação dos ritmos exaustivos de uma sociedade acelerada, mas como um índice da insignificância da própria 
vida. O que se tem neste caso não é o "tempo morto" como uma oportunidade para se pensar a respeito do sentido (ou da falta de sentido) da situação em que nos encontramos, isto é, como uma condição para a revitalização da nossa experiência de vida. Trata-se, antes, de um puro tempo vazio: uma liberação sem conteúdo, uma indeterminação que angustia, uma desaceleração que paralisa.

\section{Reaceleração exasperada}

Deparar-se com a contingência do vírus pode, desse modo, levar à inatividade. Porém, ao revelar a abertura radical do futuro, a pandemia é também um convite à ação: ela demanda que confiramos forma e sentido a um mundo que se revelou mais contingente do que imaginávamos. Uma das reações que vimos então ocorrer é a do pânico - manifestado inicialmente, entre outras maneiras, em uma prosaica corrida por papel higiênico motivada pelo boato de que os estoques logo se esgotariam. Com toda a sua urgência, sua lógica intensificadora e recursiva ("sei bem que há papel higiênico suficiente e que o boato é falso, mas e se algumas pessoas levarem o boato a sério e, em pânico, começarem a comprar reservas excessivas de papel higiênico, provocando assim uma verdadeira escassez do produto?"), ${ }^{19}$ o pânico imprime velocidade às nossas vidas, submete-as a uma reaceleração exasperada. A atividade compulsiva encobre nossa inatividade passada: podíamos ter agido antes a respeito do problema, mas não o fizemos. Limitamo-nos a lidar com ele por meio de cenários apocalípticos projetados em filmes como Contágio (2011) e em outras formas de fantasia. Mas o pânico nos conforta, sobretudo, em relação ao sentimento de impotência e à ausência de ação efetiva no presente: a ideia de que ter papel higiênico suficiente seria importante em meio a uma pandemia mortal, embora obviamente ridícula, ao menos nos dá a ilusão de estar fazendo algo a respeito.

O exemplo do consumidor de papel higiênico é anedótico, mas ajuda a iluminar um outro tipo de atividade exasperada, de implicações mais amplas: a urgência a retornar o mais rápido possível à vida anterior e, sobretudo, ao curso regular das atividades econômicas. Importa pouco que milhares de pessoas morreram, ou que muitas sentirão por meses ou anos os abalos à sua saúde; é preciso aplacar o "nervosismo" dos mercados, manter a economia girando a todo custo. O vínculo entre aceleração e capitalismo se mostra aqui com plena

\footnotetext{
${ }^{19}$ Ibid., 54.
} 
força. Fazendo com que o mundo pareça constituído por entidades a um tempo naturais e eternas - "sensíveis-suprassensíveis", como diz $\operatorname{Marx}^{20}$-, abstraídas dos processos vitais concretos que as sustentam e que são por elas engendrados, o fetichismo capitalista submete a nossa vida ao ritmo incessante da acumulação infinita. Um ritmo que não nos é simplesmente imposto de fora, mas que também acabamos por interiorizar. Daí que, para quem se habituou a viver sob o compasso das cadeias de valor, a desaceleração estabelecida pela crise pandêmica possa ser angustiante. E é por conta dessa angústia que a reaceleração, a retomada a todo custo da velocidade anterior, apareceu a muitos como o melhor caminho ou mesmo o único possível a seguir. A afirmação de que "economia é vida", dita por Jair Bolsonaro no início da pandemia, aponta exatamente para isso. Não se tratava então de reconhecer os frágeis fundamentos vivos do sistema econômico, mas, pelo contrário, de forçar a continuação da única vida que valeria a pena ser mantida: a vida abstrata da economia. O autoritarismo do governo Bolsonaro não se manifesta somente nas tentativas de calar instituições e vozes dissonantes, ou nos movimentos para capturar o Estado e reduzi-lo a seus propósitos; ele se mostra também na radicalidade com que se procura levar adiante o projeto neoliberal, com suas implicações fetichistas e aceleradoras, menosprezando toda a destruição acarretada por esse processo. Aqui, como na anedótica luta por papel higiênico, a reaceleração exasperada equivale a uma forma de pseudo-atividade: age-se compulsivamente para encobrir a própria impotência, segue-se a todo custo a vida "de sempre" para evitar o reconhecimento do caráter contemplativo das próprias ações.

\section{Desaceleração planejada}

A figura ausente em todos esses exemplos até aqui é aquela de uma prática realmente transformadora, constituída por ações que confrontem a contingência do vírus reconhecendo suas ameaças sem, contudo, sucumbir a elas ou denegá-las fetichisticamente. À desaceleração forçada imposta pela crise sanitária não se mostrou, afinal, suficiente reagir ao modo passivo de uma desaceleração imersiva ou angustiada, tampouco à maneira falsamente ativa de uma reaceleração exasperada. A pandemia exigiu a adoção de políticas públicas robustas, sobretudo nas áreas da saúde, da economia e da assistência social, de forma a limitar a

\footnotetext{
${ }^{20}$ Karl Marx, O Capital: Livro I (São Paulo: Boitempo, 2013), 147.
} 
disseminação do vírus e, ao mesmo tempo, assegurar as condições mínimas para a manutenção da vida social “normal”. Fez-se necessário, em outras palavras, um esforço planificador capaz de equilibrar-se entre as exigências de desaceleração estabelecidas pela crise sanitária e os imperativos aceleradores próprios à sociedade capitalista. A nova situação tornou urgentes uma atuação estatal mais pronunciada e uma coordenação internacional eficiente, em condições de estabelecer em grande escala medidas de desaceleração planejada.

Propostas como essas suscitaram, no entanto, uma série de preocupações. Para seus críticos, elas representariam o perigo de que, sob justificativas médicas, sejamos submetidos a um controle total de nossas vidas por aparatos estatais e supraestatais. À crise da pandemia poderia seguir-se, então, um permanente estado de exceção - uma forma de sociedade que, não acreditando em mais nada além da vida nua, esteja disposta a sacrificar tudo diante do perigo da doença. ${ }^{21}$ A denúncia dessa possibilidade por vezes assumiu, entretanto, ela mesma uma forma problemática. Ela pode levar à recusa (comum tanto à nova direita como a frações da esquerda europeia no início da crise) em aceitar a realidade plena da pandemia, reduzindo-a seja a uma trama chinesa ou globalista, seja a um projeto de poder estatal ao qual se deve resistir pela manutenção das interações sociais e dos apertos de mão. Algo dessa ordem, ainda que nem sempre amparado por tais discursos, pode ser testemunhado nas várias formas de rejeição à quarentena levadas a cabo por parcelas da população brasileira e estimuladas por Bolsonaro, mesmo em momentos críticos da disseminação do vírus. Reabertura dos shoppings e do comércio, recomeço dos campeonatos de futebol, idas em massa às praias: tudo se passa como se a (salutar) resistência a ser controlado pelo Estado conduzisse, precisamente em tempos nos quais a intervenção estatal se torna mais urgente, a uma negação maníaca da realidade da pandemia. Retorna-se, então, à defesa de uma aceleração exasperada: não se pode parar de agir, é preciso opor-se a tudo o que possa fazer obstáculo à continuação da "normalidade" pré-pandêmica. Quanto mais a continuidade da acumulação capitalista se torna inquestionável, tanto mais qualquer esforço de desaceleração passa a ser visto com desconfiança, rejeitado como exagero irrealista ou fruto de uma poderosa conspiração - mesmo quando se trata de medidas cientificamente comprovadas contra um vírus de efeitos palpáveis e cujas vítimas se multiplicam a olhos nus.

\section{Depois da pandemia?}

\footnotetext{
${ }^{21}$ Giorgio Agamben, Where Are We Now? The Epidemic as Politics (Lanham: Rowman \& Littlefield, 2021).
} 
Isso não significa, em todo caso, que essas duas perspectivas - desaceleração planejada e reaceleração exasperada - não possam vir a combinar-se entre si. Com efeito, um dos cenários projetáveis de uma vida pós-pandêmica consiste justamente numa tal articulação, tornada possível e impulsionada pelos recentes desenvolvimentos na digitalização. O prospecto de novas crises sanitárias ou outras catástrofes naturais em escala global torna imperativo que as sociedades estejam prontas para, de um momento a outro, desacelerarem-se de maneira organizada, restringindo a circulação de pessoas e atividades econômicas ou mesmo estabelecendo medidas de vigilância digital. A situação é propícia, portanto, para um aumento do poder dos Estados e dos organismos de coordenação internacional, bem como das grandes corporações do capitalismo digital. A perspectiva de um avanço no controle das vidas individuais, vislumbrada pelos negacionismos atuais, não é inteiramente descabida. Ainda que de maneira exasperada e não raro paranoica, seus temores apontam para uma ameaça real.

Onde os críticos do controle estatal se enganam, contudo, é no pressuposto de que a resistência a tal prospecto consistiria na continuação a todo custo das atividades econômicas em sua velocidade usual. A experiência atual mostra, pelo contrário, que a vida pode ser reacelerada mesmo em condições de restrição da circulação física. Graças aos meios digitais e à expansão do seu uso para atividades econômicas durante a pandemia, tornou-se possível vislumbrar um mundo no qual um grande número de pessoas permanece trabalhando em ritmo intenso mesmo sob condições de isolamento social. A desaceleração de setores ou serviços que demandam contato físico pode ser articulada à aceleração de uma quantidade cada vez maior de atividades digitalizadas. Isso não vale, decerto, igualmente para todos: como a pandemia demonstrou, a crescente digitalização das ocupações de determinados grupos, aos quais é permitido conciliar isolamento social e manutenção dos ganhos profissionais, só é possível graças à intensificação do trabalho de outros, obrigados a arriscarem sua saúde em empregos precarizados que demandam a circulação física.

Interrompendo bruscamente o curso "normal" da aceleração capitalista, a pandemia colocou em relevo os aspectos problemáticos desse processo, bem como representou um momento de abertura histórica no qual outras experiências e possibilidades de organização social do tempo puderam ser vislumbradas. Mas as reações à crise sanitária também apontam, como vimos, para a emergência de novos perigos. A perspectiva de uma reaceleração do ritmo da vida no contexto de um capitalismo de vigilância com poderes cada vez mais 
concentrados estabelece novos desafios para as mobilizações sociais. Ela impele à busca por um tipo de desaceleração planejada que, em lugar de intensificar a aceleração capitalista sob condições ainda mais desiguais e destrutivas, possa dar-se de maneira democrática, igualitária e sustentável. 


\section{Referências bibliográficas}

Agamben, Giorgio. Where Are We Now? The Epidemic as Politics. Lanham: Rowman \& Littlefield, 2021.

Bauman, Zygmunt. Liquid Modernity. Cambridge: Polity, 1999.

Bayer, Mike. Best Self: Be You, Only Better. New York: Dey Street Books, 2019.

Boltanski, Luc e Ève Chiapello. Le nouvel esprit du capitalisme. Paris: Gallimard, 1998.

Bröckling, Ulrich. Das unternehmerische Selbst: Soziologie einer Subjektivierungsform. Frankfurt am Main: Suhrkamp, 2007.

Bueno, Arthur. “¿Qué viene después de la depresión? Ocho tesis sobre la crisis de la subjetividad neoliberal y sus implicancias políticas”. Cuadernos de Teoría Social 6, no. 11 (2020): 95-120.

Dardot, Pierre e Christian Laval. La nouvelle raison du monde. Essai sur la société néolibérale. Paris: La Découverte, 2009

Ehrenberg, Alain. 'La dépression, maladie de l'autonomie? Interview d'Alain Ehrenberg”. Nervure 16, no. 3 (2003): 35-40.

-----. La fatigue d'être soi: Dépression et société. Paris: Odile Jacob, 1998.

Gramsci, Antonio. Cadernos do cárcere, vol. 3. Rio de Janeiro: Civilização Brasileira, 2007.

Han, Byung-Chul. Müdigkeitsgesellschaft. Berlin: Matthes \& Seitz, 2010.

Honneth, Axel. "Organized Self-realization: Some Paradoxes of Contemporary Individualization". European Journal of Social Theory 7, no. 4 (2004).

Lukàcs, Georg. História e consciência de classe: estudos sobre a dialética marxista. São Paulo: Martins Fontes, 2003.

Marx, Karl. O Capital: Livro I. São Paulo: Boitempo, 2013.

Marx, Karl e Friedrich Engels. O Manifesto Comunista. Porto Alegre: L\&PM Pocket, 2001.

Reckwitz, Andreas. Die Gesellschaft der Singularitäten: Zum Strukturwandel der Moderne. Berlin: Suhrkamp, 2017.

Rosa, Hartmut. "La sociedad ante la desaceleración forzada: Una interpretación sociológica de la crisis del coronavirus". Diferencia(s): Revista de teoría social contemporánea 11 (2020).

-----. Beschleunigung: Die Veränderung der Zeitstrukturen in der Moderne. Frankfurt am Main: Suhrkamp, 2005. 
-----. "Dynamic Stabilization, the Triple A. Approach to the Good Life, and the Resonance Conception”. Questions de communication 31 (2017), 437-56.

-----. “Contra a invisibilização de um 'poder fatídico': apelo à renovação da crítica do capitalismo". Perspectivas: Revista de Ciências Sociais 49 (2017), 27-8.

Sennett, Richard. The Corrosion of Character: The Personal Consequences of Work in the New Capitalism. London/New York: W. W. Norton \& Company, 1998.

Virilio, Paul. L'Inertie polaire. Paris: C. Bourgois, 1990.

Žižek, Slavoj. Pandemia: covid-19 e a reinvenção do comunismo. São Paulo: Boitempo, 2020 .

\section{Sobre o autor}

Cambiar por

Arthur Bueno. Professor assistente no Departamento de Filosofia da Goethe-Universität Frankfurt am Main (Alemanha). Professor visitante no Instituto de Psicologia da Universidade de São Paulo. Pesquisador do centro de pesquisas Normative Orders (Goethe-Universität, Frankfurt am Main) e do Núcleo Direito e Democracia (CEBRAP, São Paulo). Foi pós-doutorando da Fundação Alexander von Humboldt no Max-Weber-Kolleg da Universidade de Erfurt e na Universidade de Paris-Nanterre. É autor de Economies of Life: Simmel on Money and Art (Londres: Routledge, no prelo) e editor de Critical Theory and New Materialisms, com Hartmut Rosa e Christoph Henning (Londres: Routledge, 2021), De-centering Social Theory and Research: The Peripheral Turn in Sociology, com Mariana Teixeira e David Strecker (Londres: Routledge, no prelo), e $O$ conflito da cultura moderna e outros escritos: Georg Simmel (São Paulo: Senac, 2013), assim como de vários dossiês em revistas acadêmicas. Suas pesquisas são focadas na teoria crítica, na teoria social, nas formas de subjetividade e no sofrimento psíquico. Email: oliveira@normativeorders.net. 